\title{
O IMPACTO DA REFERÊNCIA TEMPORAL DE PASSADO SOBRE O USO DO PRETÉrito PERFEITO EM BUENOS AIRES
}

\author{
THE IMPACT OF PAST TIME REFERENCE ON THE USE OF PRETÉRITO \\ PERFECTO IN BUENOS AIRES
}

Leandro Silveira de Araújo ${ }^{1}$

\section{RESUMO}

Este trabalho analisa a variação no uso do perfeito simples (PPS - estudié) e composto (PPC he estudiado) em Buenos Aires. Nossa hipótese é que o tipo de referência temporal de passado é um fator que incide sobre o uso dessas formas verbais. A partir de um corpus de entrevistas radiofônicas, analisamos os dados tendo em vista os âmbitos temporais de passado absoluto (PA) e antepresente (AP). Como resultado, mesmo com o uso intenso do PPS, identificamos o uso do PPC tanto no PA como no AP, especialmente no AP específico e no AP ampliado.

Palavras-chave: Pretérito Perfeito. Espanhol. Variação Linguística. Tempo Verbal.

\section{ABSTRACT}

This paper analyses the variation between simple (PPS - estudié) and compound (PPC - he estudiado) forms of Perfect tense in Buenos Aires. Our hypothesis is that the kind of past reference is a factor that impacts the use of these verbal forms. From a corpus of radio interviews, we analyze the data considering the temporal contexts of absolute past (ABS) and ante-present (ANT). As a result, even with the intensive use of PPS, we identified the use of PPC in both ANT and ABS, especially in the specific ANT and the enlarded ANT.

Keywords: Perfect . Spanish. Linguistic Variation. Tense.

1 Doutor em Linguísticas e Língua Portuguesa pela Universidade Estadual Paulista (UNESP). Professor Adjunto do Instituto de Letras e Linguística da Universidade Federal de Uberlândia. Líder do Núcleo de Estudos da Norma Linguística (NormaLi/CNPq). 


\section{INTRODUÇÃO}

O interesse pelo estudo do impacto do contexto temporal sobre o uso do pretérito perfeito em Buenos Aires decorre da relativa dissonância entre a descrição apresentada em alguns trabalhos e o emprego efetivo do perfeito simples (PPS - escribi) e composto (PPC - he escrito) nessa e em outras variedades da língua.

Por um lado, alguns estudos afirmam que "no espanhol moderno baseado na melhor prática e nas melhores normas" (KANY, 1970, p. 199) emprega-se o perfeito simples para se referir ao passado absoluto (PA), isto é, "designar um fato sucedido no passado e que teve um limite neste mesmo passado" (ALARCOS LLORACH, 1980, p. 33), sem manter, portanto, relação "com o momento de fala ou com a pessoa que fala" (LENZ, 1920, p. 440). Na mesma direção, atribuise ao perfeito composto a expressão do antepresente (AP), pois com essa forma faz-se referência a situações passadas que mantêm relação com algo que ainda existe (BELLO, 1972, 2004), isto é, "uma forma do passado que se projeta em direção ao presente" (HERNÁNDEZ ALONSO, 1996, p. 428), porque a situação passada é contemplada a partir de uma perspectiva de presente, com a qual mantém uma relação de coexistência (CARTAGENA, 1999). Em síntese, a distinção proposta mais comumente pela norma gramatical defende que o PPS e o PPC coincidem em significar ação pretérita, diferenciando-se entre si, contudo, "por marcar, o primeiro, perfectividade e a falta de conexão com o presente e, o segundo, a realização de dita ação como um processo imperfectivo, que perdura (objetiva ou subjetivamente) em um espaço de tempo que [...] inclui o falante" (DE GRANDA, 2003, p. 203). As diferenças entre as duas formas podem ser observadas nos enunciados (1) e (2), em que os advérbios "ayer" (ontem) e "hoy" (hoje) evidenciam a leitura de PA e AP, respectivamente.

(1) La niña que ayer tocó con él Get Back y protagonizó uno de los momentos más lindos del recital, habló con varios medios. ${ }^{2}$

A menina que tocou "Get Back" ontem com ele e protagonizou um dos momentos mais lindos do show, falou com vários meios de comunicação [...]

(2) La ópera prima del director indio ha ganado hoy la Butaca de oro del Premio Principado de Asturias [...]. ${ }^{3}$

A ópera-prima do diretor indiano ganhou hoje a poltrona de ouro do Prêmio Príncipe de Astúrias.

2 Enunciado retirado da versão eletrônica do jornal argentino La Nación, de 18/05/2016. Disponível em: $<$ http://www.lanacion.com.ar/1899897-leila-lacaze-sobre-cantar-con-paul-mccartney-me-dio-muchosnervios>. Acesso em 18/05/2016.

3 Enunciado retirado da versão eletrônica do jornal espanhol El país, de 29/11/2014. Disponível em: <http:// cultura.elpais.com/cultura/2014/11/29/actualidad/1417288689_075919.html>. Acesso em 16/05/2016. 
Por outro lado, o uso efetivo do pretérito perfeito nas variedades do espanhol nem sempre se mostra tão categórico como retrata parte da norma gramatical. A observação do emprego dos pretéritos em algumas variedades da língua revela um comportamento diferente do descrito por muitas gramáticas, posto que se encontra tanto o PPS coocorrendo em contextos de AP (hoy), como o PPC no âmbito de PA (durante los años anteriores), tal qual apontam os enunciados (3) e (4), respectivamente:

(3) [...] también habla de la nota que salió en perfil hoy revelando la reunión que tuvo De Narváez con Aranda del Clarín. ${ }^{4}$

[...] também fala da nota que saiu no perfil hoje, revelando a reunião que teve De Narváez com Aranda, do Clarin.

(4) Durante los dos años anteriores he tenido una buena relación con el Míster. He trabajado muy bien.

Durante os dois anos anteriores, tive uma boa relação com o Mister. Trabalhei muito bem.

Considerando a divergência entre parte da norma gramatical e o uso observado em algumas variedades da língua, visamos analisar e descrever o uso do PPC e do PPS nas referências temporais de AP e PA, na variedade de Buenos Aires. Espera-se não apenas contribuir para a percepção de que o comportamento variável das formas do perfeito é uma realidade que caracteriza seu funcionamento, mas também verificar como essa heterogeneidade estrutura-se e se define na variedade bonaerense.

Antes de revisarmos o que já se descreveu sobre o uso variável das formas do pretérito em Buenos Aires e discutir nossos dados de pesquisa, passemos a uma rápida discussão teórica acerca das referências temporais de passado absoluto e antepresente.

\section{O Passado Absoluto}

O passado absoluto faz referência à anterioridade de uma situação ao momento de fala (MF). No entanto, há outros valores temporais que, direta ou indiretamente, também expressam anterioridade ao MF. A fim de melhor definir os traços do PA, a figura 1 esboça sua concepção nos termos de Guillermo Rojo (1974, 1990, 1999):

4 Enunciado retirado de uma entrevista radiofônica difundida pela rádio Cooperativa, de Buenos Aires/ Argentina (04/08/2013).

5 Enunciado retirado de uma entrevista radiofônica difundida pela rádio COPE, de Madri/Espanha $(10 / 09 / 2013)$. 
Figura 1 - A expressão do passado absoluto em espanhol segundo Guillermo Rojo ${ }^{6}$

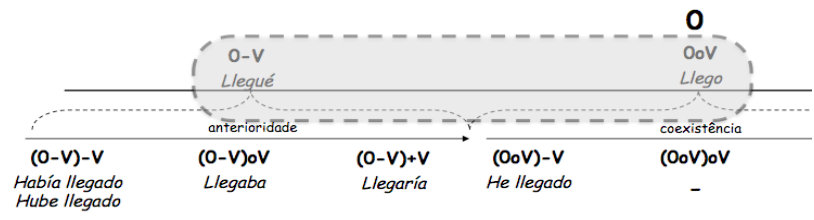

Fonte: reprodução do autor

Representa-se o PA por "0-V"(llegué - port. cheguei), o que indica que a relação de anterioridade ao momento de enunciação (0) é construída a partir de uma relação direta com " 0 " - caráter absoluto7. Cartagena (1999) associa o sentido PA ao PPS e afirma que essa forma, do mesmo modo que as demais formas de valor absoluto, delineia um segmento temporal primário a partir do ponto zero. Assim, “o presente marca a coexistência [âmbito primário de coexistência], o paralelismo de falar com um ponto do tempo real, em relação ao qual as formas do perfeito simples e do futuro indicam anterioridade [âmbito primário de restrospectividade] e posterioridade [âmbito primário de prospectividade], respectivamente" (CARTAGENA, 1999, p. 2937).

A função de PA é, portanto, fazer referência à coordenada temporal que abarca aquilo que pertence ao "âmbito primário de retrospectividade" e que, por isso, já não faz parte do presente, como em (5) e (6).

(5) El año pasado estuve haciendo la consigna de Arnold Wesker. $<B 3>^{8}$.

O ano passado estive fazendo a proposta do Arnold Wesker.

(6) Ayer hicieron su regenerativo y ya se trabajó todo el grupo junto. $<\mathrm{B} 7>$.

Ontem fizeram seu [treino] regenerativo e o grupo todo trabalhou junto.

É pertinente notar o papel dos marcadores temporais em ressaltar o sentido da forma verbal, pois ao dizer "el año pasado"/“ayer", indica-se a abrangência do "âmbito primário de restrospectividade”. Em outros termos, ao usar esses marcadores destaca-se que a situação (estuve haciendo/hicieron, trabajó)

6 Rojo $(1974,1990,1999)$ nomeia a referência fundamental do tempo de ponto central ou ponto zero (0), isto é, a origem com relação à qual se orientam de forma mediata ou imediata as situações. A partir do ponto zero, verifica-se a possibilidade de orientarmos os eventos como anteriores $(-\mathrm{V})$, simultâneos $(\mathrm{oV})$ ou posteriores $(+\mathrm{V})$.

7 Rojo (1999) chama de absolutas as relações temporais que se estruturam em relação direta com ponto zero/central, ou seja, o passado absoluto $(0-\mathrm{V})$, o presente $(0 \mathrm{oV})$ e o futuro $(0+\mathrm{V})$. Por outro lado, nomeia relativos os valores temporais que não estabelecem relação direta com o ponto zero, mas com uma referência secundária - que, por sua vez, traçará relação com o ponto central. Esse é o caso, como veremos, do valor de antepresente $((0 \mathrm{oV})-\mathrm{V})$.

8 "B2" refere-se às informações extralinguísticas do enunciado. O quadro 1 explicita as respectivas informações. 
já não faz parte do "âmbito de coexistência" - no qual vigoraria "este año" e "hoy" - mas do âmbito temporal já concluído do en el año pasado/ayer. Por fim, destacamos que a tradição gramatical é consensual em identificar expressão do PA junto ao PPS (BELLO, 1972, 1999; KANY, 1970; GILI GAYA, 1970; ALARCOS LLORACH, 1980, 2005; RAE, 1986, 2009, 2010; ROJO, 1974, 1990, 1999; TORREGO, 2002).

Uma vez caracterizado o PA, passemos à apreciação do antepresente e suas divisões.

\section{O Antepresente}

Foi Andrés Bello $(1972,2004)$ quem cunhou o termo antepresente, para quem esse valor faz referência a situações passadas que mantêm relação com algo que ainda existe. Porém, coube a outros autores uma descrição mais cuidadosa desse valor e de como se estabelece a relação da situação passada com o presente. A fim de delinear melhor esse âmbito, passemos a observação de sua categorização conforme seu potencial de ajuste: Específico, Imediato e Ampliado.

\subsection{O antepresente específico}

Mesmo se tratando de um passado, Reichenbach (2004) insere o AP no âmbito referencial concomitante (R Presente) ao momento de fala (MF), sem eliminar seu traço de anterioridade. Como ilustra a figura 2, a relação de anterioridade da situação descrita (ME) estabelece-se dentro da perspectiva referencial de presente (R Presente), o que, na notação de Reichenbach (2004), representa-se por ME-MR,MF9 , isto é, um evento (ME) passado assistido a partir de uma referência (MR) concomitante ao momento de fala (MF).

Figura 2 - A categorização do antepresente na língua segundo Reichenbach

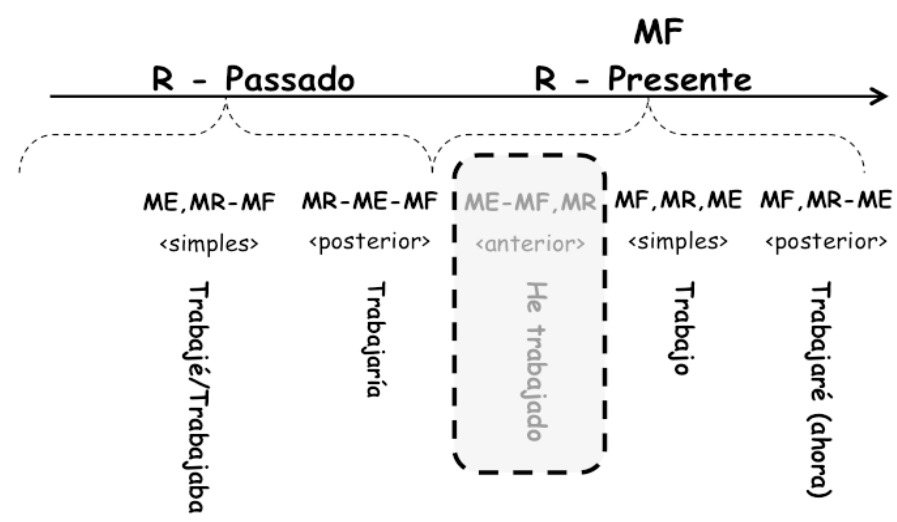

Fonte: reprodução do autor

9 Na notação do autor, entende-se travessão (-) como retrospectividade ou prospectividade e vírgula (,) como simultaneidade. ME refere-se ao momento do evento, MF, ao momento de fala e MR, ao momento de referência, que se organiza entre passado ( $\mathrm{R}$ - Passado), presente $(\mathrm{R}$ - Presente) e futuro ( $\mathrm{R}$ - Futuro). 
Assim, em (7), o enunciador insere a ação passada (ME - han dicho) em uma referência temporal (MR - esta mañana) que persiste inclusive no momento em que o enunciado é realizado (MF).

(7) En esta mañana se han dicho dos cosas eh... yo creo que es interesante ¿no? ${ }^{10}$

Nesta manhã foram ditas duas coisas eh... Eu acho que é muito interessante ¿não?

Na mesma direção, Rojo (1974, 1990, 1999) considera que o valor de antepresente é detentor de uma estruturação relativa, pois a informação temporal de anterioridade (-V) que promulga toma como referência outro valor temporal: o próprio presente $(0 \mathrm{oV})$. De modo prático, observamos em (3) "esta mañana" estabelecendo-se como referência concomitante ao ponto zero, isto é, à enunciação, e a partir da qual se estabelecerá a base temporal para construção do valor de anterioridade relativa própria do AP.

Conforme ilustra a figura 3, com o AP $((0 \mathrm{oV})-\mathrm{V}$ - he llegado), apresenta-se um evento pretérito envolvido por uma percepção de presente (MR-presente/âmbito primário de coexistência), que, por isso, guarda uma relação temporal de coexistência com o MF, ou seja, de $\mathbf{A P}^{11}$. Nos termos de Cartagena (1999, p.2941), esse valor indica que dada ação "realiza-se antes do ponto zero que nos serve de referência para medir o tempo, mas dentro do âmbito que tem como centro a coexistência ou simultaneidade desse ponto com o momento de fala".

Figura 3 - A expressão do antepresente no espanhol segundo Guillermo Rojo

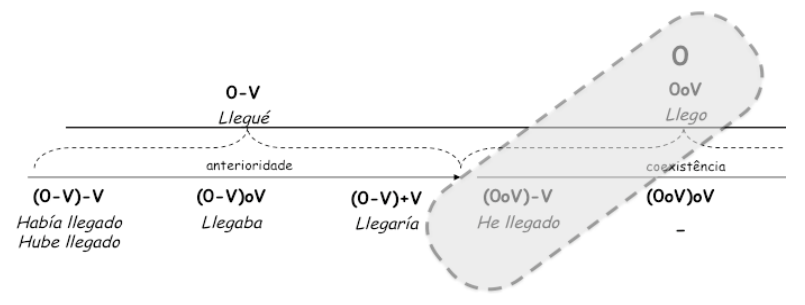

Fonte: reprodução do autor

Contudo, não é simples compreender o que pode ser considerado "relevante e/ou próximo ao MF" a ponto de ser envolvido no mesmo âmbito primário de coexistência/MR-Presente. A fim de entender a possível extensão do distanciamento existente entre o ME e o MF no valor de AP, muitos se valem da observação de elementos linguísticos recorrentes no contexto de uso das formas. Observando alguns marcadores temporais que se assemelham ao valor em análise, o AP pode se associar "com os advérbios que indicam que a ação se deu em um período de tempo no qual se 10 Enunciado retirado deuma entrevistaradiofônica difundida pelarádioCOPE, de Madri/Espanha(10/09/2013).

11 Comportamento que se difere de do valor de PA (V-O - llegué), que também corresponde a uma ação pretérita, no entanto assistida a partir de um “âmbito primário de anterioridade” (MR-pretérito), 
encontra compreendido o momento presente de quem fala", tal seria o caso de "hoy, ahora, estos días, esta semana, esta tarde, esta mañana, este mes, el año en curso, esta temporada" etc. (ALARCOS LLORACH, 1980, p. 24). Apesar da grande diferença na amplitude temporal abarcada por esses marcadores, qualquer um deles envolve em um mesmo âmbito (MR) tanto a situação descrita como o momento de fala. Ou seja, em enunciados como (8a) e (8b), consideramos que tanto o acontecimento ('ha ganado') como a enunciação (MF) compartilham da mesma envoltura temporal: "hoy” (hoje) ou “este año" (este ano) - respectivamente.

(8a) La ópera prima del director indio ha ganado hoy la Butaca de oro [...].12

A ópera prima do diretor indiano ganhou hoje a poltrona de ouro do Prêmio Príncipe de Astúrias.

(8b) La ópera prima del director indio ha ganado este año la Butaca de oro.

A ópera prima do diretor indiano ganhou este ano a poltrona de ouro do Prêmio Príncipe de Astúrias.

Além disso, nas orações de (8), a recorrência do valor de AP mostra que não parece ser fundamental que a distância existente entre a situação (ME) e o MF seja igual ou menor que um dia, mas que é suficiente haver uma relação temporal imbricada entre elas.

Por fim, salientamos que a tradição gramatical é consensual em identificar a expressão do AP específico junto ao PPC (BELLO, 1972, 1999; KANY, 1970; GILI GAYA, 1970; ALARCOS LLORACH, 1980, 2005; RAE, 1986, 2009, 2010; ROJO, 1974, 1990, 1999; TORREGO, 2002). Como já destacado por alguns autores, há dois outros subâmbitos temporais resultantes do desdobramento perceptível do momento de referência: o de AP imediato e o de AP ampliado, os quais descreveremos nas linhas seguintes.

\section{2 $O$ antepresente imediato}

Encontramos nesse subvalor de $\mathbf{A P}$ as mesmas características já examinadas de modo geral no valor de AP específico; no entanto, acresce-se a seu campo semântico a especificidade de um traço imediato, ou seja, o momento de referência (MR) que envolve tanto a situação descrita (ME) como o MF passa a ser mais limitado, obrigando que dada situação esteja mais próxima ao momento de fala. Esse uso é verificado em (9):

12 Enunciado retirado da versão eletrônica do jornal espanhol El País, de 29/11/2014. 
(9) $[\ldots]$ algo que ha sorprendido en las últimas horas tiene que ver con el crecimiento de algunos proyectos que vienen desde China directamente. ${ }^{13}$

[...] algo que surpreendeu nas últimas horas tem a ver com o crescimento de alguns projetos que vêm direto da China.

O enunciado (9) mostra que, graças ao uso do marcador temporal "en las últimas horas", a situação descrita ("ha sorprendido") terminou muito recentemente. No entanto, nota-se que a maioria dos estudos segue permeada por uma dificuldade em delimitar a dimensão do "âmbito primário de coexistência" nesse valor marcado por um traço de maior instantaneidade. Na tentativa de resolver essa questão, alguns pesquisadores chamam esse valor de hodierno ou hudiernal $\mathbf{~}^{\mathbf{1 4}}$, indicando, assim, que a delimitação da distância existente entre o momento da fala e o momento do evento se insere nos limites de um dia.

Ressaltamos que a diferença existente entre o valor de AP específico e o de imediato (hodierno) reside fundamentalmente na extensão do "âmbito primário de coexistência" (MR). Por isso, parece apropriado tratar o segundo sentido como uma delimitação do AP específico, cujo âmbito de coexistência pode se estender mais livremente e, consequentemente, envolver situações mais distantes do MF. Mais uma vez, destaca-se a posição da tradição gramatical da língua em atribuir ao PPC a expressão do AP imediato (BELLO, 1972, 1999; KANY, 1970; GILI GAYA, 1970; ALARCOS LLORACH, 1980, 2005; RAE, 1986, 2009, 2010).

\subsection{O antepresente ampliado}

Identificado pela norma gramatical como experiencial, o valor aqui denominado AP ampliado indicanos que uma situação se manteve, pelo menos uma vez, durante algum tempo amplo, pouco especificado e anterior ao MF. Há de se considerar que a ausência de um delimitador temporal explícito pode favorecer uma interpretação mais abrangente do âmbito temporal em que dado evento aconteceu. Assim, o enunciador e/ou o enunciatário pode considerar que a situação descrita sucedeu em qualquer momento durante um extenso período, que não raramente pode envolver até toda a existência do experimentador. Assim, o enunciado (10) - mesmo trazendo explicitamente um especificador temporal ("en mi larga carrera") ilustra-nos como o "âmbito primário de referência" (MR presente) se arrasta a ponto de envolver um longo período da existência do enunciador. É a ampliação do momento de referência que permite estabelecer uma relação entre a situação descrita e o MF, facultando, de alguma maneira, a leitura de AP.

13 Enunciado retirado de uma entrevista radiofônica difundida pela rádio LV10, de Mendoza/Argentina $(13 / 08 / 2010)$.

14 Do latim, hodiernus, que quer dizer "do dia de hoje" (RAE, 2009, p.1730). 
(10) $[\ldots]$ en mi larga carrera de actor he dirigido espectáculos musicales, como los del Carmen Flores $<\mathrm{B} 3>$.

[...] em minha longa carreira de ator dirigi espetáculos musicais, como os de Carmen Flores.

Figura 4 - O valor antepresente ampliado

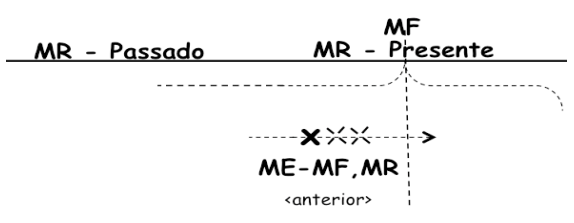

Fonte: reprodução do autor

O AP ampliado pode ser observado na figura 4, na qual as letras (x) tracejadas mostram o desconhecimento da quantidade de vezes em que ocorre o evento. Por sua vez, a linha temporal tracejada acusa a indefinição do momento exato em que se deu a situação. Podemos observar, contudo, que, apesar da imprecisão, a situação continua sendo tratada dentro do "âmbito primário de coexistência" (MR-Presente), já que o falante pode estendê-lo a ponto de envolver toda a vida.

O Manual de la Nueva Gramática de la Lengua Española (RAE, 2010, p. 429) afirma que "últimamente, en estos tiempos, en estos dias, as fórmulas a lo largo de + grupo nominal quantitativo temporal, en $\{$ más $\sim$ menos\} de + grupo nominal quantitativo temporal ou $\{$ desde $\sim$ hasta $\}+$ advérbio ou grupo nominal de sentido temporal" são exemplos de expressões temporais do espanhol que corroboram o valor de AP ampliado. Há ainda outros marcadores temporais que não delimitam o âmbito temporal em que uma situação ocorre, mas salientam o sentido prototípico de indeterminação temporal associado a esse uso. Esse é o caso dos advérbios 'nunca' e 'siempre' (que consideram toda a vida do indivíduo) e das locuções 'alguna vez' e 'en alguna ocasión'(as quais se relacionam à quantidade de ocorrências do evento).

A indeterminação do momento passado em que se deu o evento pode estar também associada a perguntas e à negação, tal como verificamos em (11) e (12), respectivamente:

(11) ¿Se han enfrentado alguna vez o esta es la primera vez? <B7> Enfrentaram-se alguma vez ou esta é a primeira vez?

(12) Hasta el fondo mismo, hasta donde no ha llegado absolutamente nadie. ${ }^{15}$ Até o fundo do mar mesmo, até onde não chegou absolutamente ninguém.

15 Enunciado retirado de uma entrevista radiofônica difundida pela rádio LV10, de Mendoza/Argentina $(13 / 09 / 2010)$. 
Por fim, o estudo do valor de antepresente revela que suas nuances correspondem à sistematização de diferentes amplitudes temporais, as quais, a despeito de suas particularidades, têm em comum a retratação de uma situação pretérita $(\mathrm{ME})$ que ocorre em um âmbito temporal $(\mathrm{MR})$ ainda vigente no momento de fala (MF). Isso posto, não raramente, o falante pode intervir na descrição dos fatos que apresenta, inserindo os acontecimentos narrados dentro de um intervalo temporal que, para o enunciador, ainda se encontra em vigor - especialmente quando se trata do AP ampliado. Por outro lado, o PA se distingue por inserir a situação descrita em uma perspectiva temporal de passado e já concluída quando apresentada pelo enunciador - rompendo, portanto, a relação temporal entre o momento do evento e o momento de fala.

A fim de complementar o referencial teórico que nos servirá de base para análise dos dados deste estudo, apresentaremos, na seção seguinte, resultados de outros trabalhos sobre o uso do PPC e do PPS no espanhol argentino, e mais especificamente, em Buenos Aires.

\section{O uso do PPS e do PPC em Buenos Aires: revisão bibliográfica}

As pesquisas de maior repercussão sobre o comportamento das formas do pretérito perfeito na Argentina desenvolveram-se tendo em vista, fundamentalmente, as variedades bonaerense e noroeste ${ }^{16}$. Além disso, é possível ainda subdividir esses trabalhos em dois tipos de abordagens: (i) uma preocupada com a norma linguística de alguma(s) das regiões argentinas e (ii) outra interessada em descrever a manifestação das formas do pretérito perfeito na América e que, para isso, apresenta brevemente a situação dos pretéritos na Argentina.

Atendo-nos inicialmente a essa última abordagem, observamos que trabalhos como os de RAE (1986), Lamiquiz Ibañez (1969), Moreno Fernández (2000) e Oliveira (2007) afirmam a existência de um uso comum para todo o país - no qual predomina a forma do PPS.

Segundo a conclusão dos autores, a generalização da forma de pretérito perfeito simples parece decorrer da generalização do uso observado na norma bonaerense às demais variedades diatópicas do país. Por outro lado, uma segunda postura, que opõe o comportamento do PPC na região noroeste/ norte ao comportamento na região bonaerense, pode ser observada em trabalhos desenvolvidos por Kany (1970), Gutiérrez Araus (2001), Alarcos Llorach (2005) e Jara Yupanqui (2009), dentre os quais retiramos, a título de exemplo, a seguinte asseveração:

16 Incluem-se na zona noroeste do país as províncias de Jujuy, Salta, Catamarca, La Rioja, Santiago del Estero e San Miguel de Tucumán. 
“[...] o panorama de uso das formas canté/he cantado nesse grande país é variado e aparecem duas zonas claramente diferenciadas em relação ao assunto: por um lado, o norte do país: Tucumán, Salta etc. e, por outra parte, Buenos Aires e o Litoral" (GUTIÉRREZ ARAUS, 2001, s/n, tradução nossa) ${ }^{17}$.

Soma-se a essa proposta de bipartição, a observação do maior índice de ocorrência do PPS sobre o PPC na área do Río de la Plata. Baseando-se no estudo de Kubarth (1992), Gutiérrez Araus (2001) faz-nos saber que, apesar da significativa diminuição do uso do PPC em Buenos Aires, ainda trata-se de uma forma viva nessa zona. Contudo, considera-se que já

[...] não funciona como forma de anterioridade imediata à enunciação ou antepresente, como também não se emprega em momentos culminantes ou emotivos da narração ou com valor enfatizador, no entanto, sim, se emprega como forma de valor resultativo com relevância no presente (GUTIÉRREZ ARAUS, 2001, s/n, tradução nossa) ${ }^{18}$.

Além disso, a pesquisa de Vidal de Battini (1964), destinada exclusivamente à descrição do espanhol na Argentina, informa-nos que

\begin{abstract}
Na fala do país não há diferenças de sentido entre o pretérito (simples) e o perfeito (composto), mas sim, há preferências regionais. Há preferência marcada pelo uso do pretérito perfeito na região Noroeste, particularmente a partir de Tucumán até a fronteira com a Bolivia [...]. No resto do país, e particularmente na grande zona de influência de Buenos Aires, preferem-se as formas do pretérito (simples) [...]. Na região central, as duas formas alternam-se [...] com maior tendência às formas simples. (VIDAL DE BATTINI, 1964, p.189, tradução nossa) ${ }^{19}$.
\end{abstract}

Em outras palavras, conforme aponta o trabalho levado a cabo nos anos 1960, deveríamos observar no espanhol da Argentina (i) equivalência de sentido expresso pelo PPS e pelo PPC, confirmando, portanto, uma variável linguística ao longo de todo território; (ii) a preferência regional pelo uso de uma ou outra variante; (iii) a existência de três padrões de uso, ou seja, além dos dois já conhecidos, haveria um terceiro verificável na região central - tida como zona de transição. Por outro

17 “[...] el panorama de uso de las formas canté/he cantado en este gran país es variado y aparecen dos zonas claramente diferenciadas al respecto: por un lado el norte del país: Tucumán, Salta, etc. y por otra parte, Buenos Aires y el Litoral" (GUTIÉRREZ ARAUS, 2001, s/n).

18 “...] no funciona como forma de anterioridad inmediata a la enunciación o antepresente, como tampoco se emplea en momentos culminantes o emotivos de la narración o enfatizador, sin embargo sí se emplea como forma resultativa con relevancia del presente (GUTIÉRREZ ARAUS, 2001, s/n).

19 En el habla del país no hay diferencias de sentido entre el pretérito (simple) y el perfecto (compuesto), pero sí hay preferencias regionales. Hay marcada preferencia por el uso del pretérito perfecto en la región Noroeste, particularmente desde Tucumán hacia el límite con Bolivia [...]. En el resto del país, y particularmente en la gran zona de influencia de Buenos Aires, se prefieren las formas del pretérito (simple) [...]. En la región central alternan las dos formas [...] con mayor tendencia a las formas simples (VIDAL DE BATTINI, 1964, p.189). 
lado, apesar dessas informações distribucionais, notamos no trabalho de Vidal de Battini (1964) a carência da informação sobre qual é o sentido que ambas as formas expressam.

Também procurando estabelecer um panorama de uso do PPC/PPS em toda a Argentina, Múgica (2007) se mostra defensora da tese de que ambas as formas compartilham exatamente o mesmo significado e que, por isso, deveriam ser tratadas como variantes cuja intensificação de uso seria determinada pela norma presente em cada uma das regiões do país. Nas palavras da autora:

[...] a distinção perfeito simples/perfeito composto não apresenta diferenças de significado. Se alternassem nos falantes particulares, tratar-se-ia verdadeiramente de uma variação já que não aportariam diferenças de significado. Mas com diferenças de região a região, no mapa da Argentina, se escolhe um ou outro (MÚGICA, 2007, p.19) ${ }^{20}$.

Kubarth (1992) desenvolveu o primeiro estudo mais substancial sobre a situação dos pretéritos em Buenos Aires. Valendo-se de um modelo de entrevista próprio da metodologia sociolinguística, o autor avalia o uso feito por 107 informantes de diferentes idades (a. 13 a 30 anos, b. 31 a 49 anos e c. 49 a 75 anos) e classes sociais (baixa, média e alta) e conclui que a referência a situações terminadas antes do momento de fala faz-se preferencialmente mediante o perfeito simples - seja ela de AP ou PA, de maneira que, para o autor, o critério da distância temporal não incide na seleção de um ou outro pretérito na modalidade falada, em Buenos Aires (KUBARTH, 1992, p. 561). O autor ainda demonstra que o perfeito composto é usado com maior frequência para expressar uma situação que persiste até o momento de fala (continuidade). Por fim, identifica uma maior frequência do PPC junto à população mais velha, indicando a possibilidade de que essa forma possa ser eliminada no futuro (KUBARTH, 1992, p. 565).

García Negroni (1999), por sua vez, recorre à dicotomia temporal de Benveniste (2005), segundo a qual se opõe o "tempo da história" ao "tempo do discurso" 21 , para demonstrar que, na variedade

$20[\ldots]$ la distinción perfecto simple/perfecto compuesto no arroja diferencias de significado. Si en los hablantes particulares alternaran, se trataría verdaderamente de una variación ya que no aportarían diferencias de significado. Pero con diferencias de región a región, en el mapa de la Argentina, se elige uno u otro (MÚGICA, 2007, p.19)

21 O tempo da história caracteriza-se pela narrativa dos acontecimentos pretéritos sem qualquer intervenção do locutor, excluindo, por conseguinte, toda forma linguística tida como autobiográfica. Na língua francesa, esse sistema comportaria três tempos: o aoristo (passé simple), o imperfeito e o mais-que-perfeito. O tempo do discurso, por sua vez, é encontrado em toda enunciação que suponha um locutor e um ouvinte e, no primeiro, a intenção de influenciar, de algum modo, o outro. Nota-se, portanto, um maior grau de subjetividade nessa perspectiva. O perfeito composto surge como uma forma correferente ao aoristo no plano do discurso, com a particularidade de estabelecer um laço vivo entre o acontecimento passado e o presente no qual a sua evocação se dá. 
bonaerense, o PPC e o PPS só entrariam em variação no tempo do discurso (antepresente), já que o PPS é a forma exclusiva para referir-se ao tempo da história (passado absoluto). No entanto, a variação entre ambas as formas do pretérito perfeito no tempo do discurso seria dissolvida a partir da observação do traço de relevância presente, posto que, segundo a autora, com o PPC, o locutor expressaria uma maior pertinência da situação denotada para o momento de enunciação. Desse modo, a distinção no uso do PPS e do PPC permitiria marcar diferentes graus de adesão ou distanciamento em relação ao que se enuncia, orientando, por conseguinte, certas interpretações, em detrimento de outras (GARCÍA NEGRONI, 1999, p.54). Contudo, tendo em vista seus objetivos e limitações de análise, a autora é reticente em categorizar esse comportamento do pretérito perfeito como geral na norma bonaerense.

Os estudos conduzidos por Oliveira $(2007,2010)$ corroboram, de modo mais sistemático e preciso, as indicações de García Negroni (1999). Em seu primeiro estudo, Oliveira (2007) indica que, em artigos escritos de jornais portenhos, o PPS é a única forma identificada no contexto de PA. Quanto ao contexto de AP, também se observa o uso recorrente do PPS; contudo, com uma pequena proporção do PPC (4,5\%) ocorrendo em aparente variação. No estudo seguinte, Oliveira (2010) aponta que o uso do PPC em Buenos Aires apresenta os valores de continuidade e de relevância presente (Oliveira, 2010, p. 212).

Contrastando dois gêneros discursivos (artigos de jornais e entrevista sociolinguística), Santos (2009) observa que em Buenos Aires há um significativo incremento percentual no uso da forma composta com a passagem para a modalidade oral (de 5\% para 21\%). Atenta às ocorrências do PPS e do PPC nos âmbitos de antepresente e passado absoluto, a pesquisadora nota que, em ambos os gêneros discursivos e âmbitos temporais, há variação entre as duas formas do pretérito perfeito - comportamento que é marcado por uma maior recorrência constante da forma simples. Contudo, notamos que, conforme se avança do gênero escrito para o oral e do âmbito de PA para o AP, maior é o incremento na recorrência da forma composta.

Ainda sobre o comportamento dos pretéritos na variedade da capital argentina, destacam-se os trabalhos substanciais conduzidos por Rodriguez Louro (2008, 2009, 2010 e 2011). Dentre as muitas contribuições aportadas pela autora, destacamos a descrição do uso mais intenso da forma composta relacionado à expressão de uma situação genérica ocorrida em um passado indefinido. Em outros termos, o PPC, em Buenos Aires, faz referência a situações (potencialmente) realizadas em um âmbito de passado que não é identificado, delimitado ou reconhecido (RODRIGUEZ LOURO, 2009, p. 250; 2011, p. 60), tal como se observa em (13) e (14) - reproduzidos de Rodriguez Louro (2010, 
p. 11). Notemos que a ausência de um elemento que permita uma ancoragem temporal específica e a presença do nome coletivo e pouco definido (personas) do enunciado (13) ou do quantificador mucho, em (14), favorecem a leitura de passado genérico.

(13) He atendido personas que han venido del extranjero.

Atendi/tenho atendido pessoas que vieram do exterior.

(14) He viajado mucho pero en viajes de turismo.

Viajei/tenho viajado muito, mas viagens a turismo.

Em adendo, a autora ainda identifica o uso da forma composta expressando os sentidos de resultado, continuidade e experiência (AP ampliado) (RODRIGUEZ LOURO, 2010, p.21). Contudo, defende que os sentidos de continuidade e resultado tornam-se cada vez menos recorrentes junto à forma composta, já que o PPS começa a expressar esses valores, bem como os de passado absoluto e de antepresente (imediato e específico) (RODRÍGUEZ LOURO, 2011, p. 67). Em suas palavras:

O perfeito composto em Buenos Aires tem diminuído sua frequência de uso a partir do século XIX e o perfeito simples invadiu os espaços ocupados antes pelo PPC. Como resultado, as várias funções expressas pela forma composta (incluindo resultado, continuidade, relevância presente e AP imediato) no século XIX são, na atualidade, expressas fundamentalmente pelo PPS - às vezes em combinação com marcadores temporais (RODRÍGUEZ LOURO, 2009, p. 250, tradução nossa) ${ }^{22}$.

Em síntese, diante do complexo cenário esboçado, Rodriguez Louro conclui que, na região bonaerense, utiliza-se o PPC de forma limitada, mas estatisticamente significativa, e em diferentes contextos. Além disso, "a maior frequência de uso do PPC no registro formal poderia assinalar que essa é uma forma de prestígio no espanhol bonaerense” (RODRIGUEZ LOURO, 2008, p.20).

Finalmente, os trabalhos que realizamos sobre o comportamento da forma composta nas variedades diatópicas da Argentina (ARAUJO, 2012, 2013, 2015) identificam, em Buenos Aires, a menor recorrência do PPC (6\%) - quando comparamos sua frequência com as outras seis regiões do país $^{23}$. Em relação aos valores atribuídos ao PPC nessa variedade, identificamos uma maior recorrência do uso do PPC expressando resultado (55\%), experiência (AP ampliado) (25\%) e passado

22 The ARPS Present Perfect has dwindled in usage frequency since the 19th century and the Preterit has invaded the spaces erstwhile occupied by the Present Perfect. As a result, the various functions expressed by the Present Perfect (including result, continuity, current relevance, and hot news) in the 19th century are currently mostly fulfilled by the Preterit, sometimes in combination with TAs (RODRÍGUEZ LOURO, 2009, p. 250)

23 A recorrência do PPC nas demais variedades diatópicas do país divide-se em: Patagônia (7\%), Nordeste (9\%), Litoral (10\%), Cuyo (15\%) Noroeste (25\%) e Central (28\%) (ARAUJO, 2013, p.208). 
absoluto (15\%). Contudo, alguns poucos usos foram identificados com o valor de continuidade (5\%) (ARAUJO, 2013, p. 208).

A seguir, dirigiremos nossa atenção à análise dos dados coletados para o cumprimento deste trabalho. Desse modo, expomos na seção seguinte os aspectos metodológicos deste estudo.

\section{Aspectos metodológicos: o corpus de análise}

Nosso estudo parte de um corpus compilado para os propósitos pautados, de modo que a opção pelo gênero "entrevista radiofônica" se deve ao fato de que esse gênero apresenta uma variedade linguística relativamente próxima à realidade cotidiana de fala da comunidade investigada, além de possibilitar uma diversidade temática e de tipologia textual (ARAUJO, 2017) que favorece o estudo dos fenômenos em pauta. Isso porque, para descrever eventos (descrição), ordená-los temporalmente (narração), explicar e analisar situações (exposição), bem como para contrapor ideias (argumentação), parecem ser necessárias formas verbais vinculadas a coordenadas temporais que englobam do pretérito até o presente - contextos em que estão os valores de PA e AP. Ao recorrermos às entrevistas radiofônicas, não apenas garantimos o acesso remoto a um material autêntico e diversificado, mas também viabilizamos a obtenção das informações sociolinguísticas de que necessitamos - ora por inferência na própria entrevista, ora por contato direto com as rádios ou por meio de redes sociais (ARAUJO, 2017).

A forma básica de obtenção das entrevistas foi através dos áudios disponibilizados pelas emissoras. Quando não dispostos para download, foi utilizado o software Audacity 1.3 para gravação das entrevistas. As mais de 2 horas de gravações referentes às 8 entrevistas radiofônicas forneceramnos mais de 21 mil palavras. Em relação à recorrência das formas em análise, observamos 562 casos dos pretéritos. A fim de organizar a referenciação da fonte dos enunciados que serão apresentados ao longo da discussão, o quadro 1 expõe, a partir do código da entrevista (Cód.), as informações sobre a rádio de origem, data de gravação da entrevista e sua duração (Tempo), número de participantes envolvidos no diálogo (N. Infor) e a temática discutida. 
Quadro 1 - A relação de entrevistas que compõem o corpus

\begin{tabular}{|c|c|c|c|c|c|c|c|}
\hline Rádio & Cód. & Data & Tempo & $\begin{array}{c}\text { N. } \\
\text { Infor }\end{array}$ & $\begin{array}{l}\text { Faixa } \\
\text { etária }\end{array}$ & $\begin{array}{c}\text { N. } \\
\text { Mulher }\end{array}$ & Temática \\
\hline Continental & B1 & 02.06 .2010 & $10^{\prime} 07^{\prime \prime}$ & 2 & 62 a 63 & 1 & $\begin{array}{c}\text { Sociedade. Serv. } \\
\text { Social. }\end{array}$ \\
\hline \multirow[t]{2}{*}{ Palermo } & B2 & 29.09 .2010 & $10^{\prime} 50^{\prime \prime}$ & 2 & 37 a 38 & 0 & $\begin{array}{c}\text { Artes. Artes } \\
\text { Plásticas. }\end{array}$ \\
\hline & B3 & 29.09 .2010 & 16’30" & 3 & 36 a 70 & 2 & Artes. Teatro. \\
\hline \multirow{5}{*}{ Cooperativa } & B4 & 04.08 .2013 & 19'16" & 2 & 43 a 53 & 0 & Política. Gênero. \\
\hline & B5 & 04.08 .2013 & $33^{\prime} 02^{\prime \prime}$ & 2 & 50 a 53 & 1 & Política. Eleições. \\
\hline & B6 & 14.08 .2013 & $11^{\prime} 48^{\prime \prime}$ & 3 & 45 a 68 & 0 & Esporte. Futebol. \\
\hline & B7 & 10.09 .2013 & 13'33" & 4 & 40 a 68 & 0 & Esporte. Futebol. \\
\hline & B8 & 07.08 .2013 & 06'24"' & 3 & 28 a 48 & 0 & Esporte. Futebol. \\
\hline
\end{tabular}

Fonte: reprodução do autor

\section{0 impacto do tipo de referência temporal sobre o uso do Pretérito Perfeito}

Conforme mostra a Tabela 1, sem considerar as especificidades funcionais presentes nos usos de cada forma, encontraremos no corpus compilado resultados marcadamente favoráveis ao uso do PPS em Buenos Aires e um percentual praticamente residual da forma composta.

Tabela 1 - A distribuição do PPS e do PPC desconsiderando os contextos temporais

\begin{tabular}{c|c|c}
\hline PPC & 52 & $9 \%$ \\
\hline PPS & 499 & $91 \%$ \\
\hline Total & 551 & $100 \%$ \\
\hline \multicolumn{3}{l}{ Fonte: reprodução do autor }
\end{tabular}

Contudo, como discutiremos a seguir, a simples recorrência das duas formas não permite identificar os contextos de ocorrências de cada uma das variantes e compreender o status da forma composta nessa variedade. Partimos da hipótese de que o tipo/abrangência da referência temporal de anterioridade é um fator determinante no uso das formas do pretérito perfeito. Para verificar essa hipótese, discutimos a seguir a correlação das formas de PPS e PPC com os valores de antepresente e passado absoluto.

\subsection{O antepresente}

Conforme pontuamos, a tradição gramatical da língua espanhola considera o âmbito do antepresente (e seus subâmbitos) como o contexto de uso do PPC (BELLO, 1972, 1999; KANY, 1970; GILI GAYA, 1970; ALARCOS LLORACH, 1980, 2005; RAE, 1986, 2009, 2010; ROJO, 
1980, 2005; TORREGO, 2002). Contudo, uma análise detalhada desse contexto revela, em Buenos Aires, um uso aparentemente divergente ao descrito pela norma-padrão (Tabela 2).

Tabela 2 - A expressão dos subâmbitos de antepresente em Buenos Aires ${ }^{24}$

\begin{tabular}{c|c|c|c|c|c|c}
\cline { 2 - 7 } & \multicolumn{6}{c}{ ANTEPRESENTE } \\
\cline { 2 - 7 } & \multicolumn{2}{c}{ Imediato } & \multicolumn{2}{c}{ Específico } & \multicolumn{2}{c}{ Ampliado } \\
\hline PPS & 42 & $100 \%$ & 72 & $87 \%$ & 41 & $55 \%$ \\
\hline PPC & 0 & $0 \%$ & \multirow{2}{*}{11} & $13 \%$ & \multirow{2}{*}{33} & $45 \%$ \\
\hline Total & 42 & $100 \%$ & 83 & $100 \%$ & 74 & $100 \%$ \\
\hline
\end{tabular}

Fonte: reprodução do autor

De acordo com a tabela 2, nota-se, no AP imediato, o uso exclusivo do PPS (100\%) e um gradual aumento da forma composta à medida que se amplia a referência de antepresente, de modo que no AP específico temos $13 \%$ de ocorrências da forma composta e 45\%, no AP ampliado. Há, no entanto, um ponto importante: em nenhum dos valores possíveis predomina o PPC. O que fica claro é que no caso de antepresente ampliado há maior variação.

A partir dessa primeira análise já é possível afirmar que a abrangência da referência temporal de anterioridade é um fator determinante no comportamento das formas do pretérito perfeito.

Os enunciados (15) e (16) ilustram o uso do PPS no contexto de AP imediato. Os marcadores temporais "recién" e "antes de salir al aire" indicam o valor hodierno vigente.

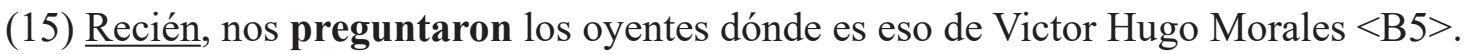

Há pouco, os ouvintes nos perguntaram onde fica essa coisa de Victor Hugo Morales.

(16) $[\ldots]$ como te comenté antes de salir al aire, empecé en la radio de muy chico $<$ B3 $>$.

[...]como te comentei antes de sair ao ar, comecei na rádio quando era muito pequeno.

Os contextos de AP específico e AP ampliado serão analisados separadamente a fim de melhor avaliar aparente variação das formas do pretérito perfeito nos respectivos contextos.

24 Tendo em vista a decisão teórico-metodológica de separar as ocorrências do contexto de antepresente das verificadas no contexto de passado absoluto, os quantitativos presentes na tabela 2 excluem os dados referentes ao passado absoluto, expostos na tabela 3 . Por isso, há uma discrepância entre os dados da tabela 1 com os dados das tabelas 2 e 3 . 


\subsubsection{O AP específico}

O estudo das características aspectuais da base verbal oferece-nos alguns indícios que nos permitem associar o uso do PPC à expressão de um valor de continuidade. Nesse sentido, o modo de ação parece ser o grupo de fatores com maior influência sobre o uso da forma composta, posto que a recorrência de uso do PPC com verbos estativos mostra-se mais expressiva (passa de 13\% de recorrência geral do PPC para 26\%) e o peso relativo desse fator sobre o uso da forma composta é de $[0,78]$.

(17) Estoy feliz [en los últimos días] porque hemos tenido una distinción maravillosa ya que nos eligieron cómo tesis final de la carrera de artes de la UBA $<$ B3 $>$.

Estou feliz [nos últimos dias] porque tivemos uma distinção maravilhosa, já que nos escolheram como trabalho final no curso de artes da UBA.

O enunciado (17) mostra o uso do PPC com verbo estativo (“hemos tenido una distinción”), fazendo referência a uma situação que ainda perdura, de algum modo, no momento de fala. Assim, a repercussão dessa situação no presente é destacada pelo estado de felicidade em que se encontra o enunciador ("estoy feliz"). Por outro lado, no mesmo enunciado, observa-se o uso do PPS ("nos eligieron") para se referir a uma ação pontual e télica (achievement) que, como tal, não persiste até o momento de fala. Ainda sobre o modo de ação, os verbos de achievement ${ }^{25}$ ocorrem com maior frequência em PPS (93\%).

Sobre a tipologia de orações (afirmativas, negativas ou interrogativas), é pertinente destacar a relevância que as orações interrogativas parecem exercer sobre o uso do PPC, já que o percentual de uso do PPC nesse contexto frasal é de $25 \%$, com peso relativo de [0,59].

(18) ¿Has visto una película con Richard Gere? Yo no la vi [todavía] <B1>. Você viu uma película com Richard Gere? Eu não a vi [ainda].

A observação do contexto interrogativo permite-nos entender a possível causa do favorecimento da forma composta em detrimento da simples, nesse contexto frasal. Conforme se nota em (18), o enunciador vale-se da forma composta ("has visto") para se referir a uma "ação potencialmente efetivada" dentro da referência temporal instaurada indiretamente: "período desde quando o filme foi lançado até o MF, quando ainda permanece em cartaz". Por se inserir em contexto de interrogação,

25 Os verbos de estado são marcados pelos traços de duração e atelicidade, ao passo que o verbos de achievement se definem pelos traços contrários, isto é, não duração e telicidade. 
sabemos que o enunciador não tem conhecimento da efetiva realização da ação por parte de seu interlocutor.

Em contrapartida, o enunciador pode afirmar com segurança sobre aquilo que conhece: sua própria experiência. De modo que se vale do PPS (“vi”) para referir-se a uma situação passada definida - no caso, a ausência dela. Como já destacado, Rodríguez Louro $(2009,2011)$ define que o PPC é utilizado na variedade portenha para fazer referências a situações passadas genéricas/indefinidas, ao passo que o PPS é usado para referenciar uma situação passada específica e definida.

Por fim, uma análise das variáveis extralinguísticas mostra-nos a maior ocorrência do PPC entre homens ( 10 de 11 casos do PPC no AP específico) - fator com maior percentual e peso sobre o uso do PPC $(16 \% /[0,73])$-, ao passo que a forma simples é mais recorrente entre as mulheres (95\%). Uma vez que a forma simples mostra-se mais frequente entre as mulheres, é possível pensar que o PPS integra a norma de prestígio na expressão do AP específico, em Buenos Aires. Esse comportamento é ainda mais evidente se consideramos o alto percentual geral do PPS nesse contexto temporal de análise. Recordamos, contudo, que devido à limitação de nossos dados em equiparar sistematicamente a quantidade de informantes de ambos os gêneros/sexos, essas informações requerem uma avaliação mais estendida.

Quanto à faixa-etária, observamos que quanto mais velho é o falante, maior é a incidência da forma composta, de tal maneira que não se observa o PPC na fala de abaixo de 35 anos e se nota o aumento no percentual de uso dessa forma entre falantes acima de 55 anos $([0,54] / 20 \%)$. Com um comportamento inversamente proporcional, o PPS torna-se a variante categórica entre os mais jovens e pouco menos recorrente entre os mais velhos (80\%). Essa configuração parece indicar que o PPC passa por um processo de desuso na expressão do AP específico à medida que o PPS mantém-se mais favorecido pela norma bonaerense - a exemplo do que foi atestado por Kubarth (1992).

Para concluir, o PPS comporta-se como a forma de prestígio na expressão do AP específico em Buenos Aires, o que é evidenciado não apenas pelo alto percentual de ocorrência, mas também pelo favorecimento na fala feminina e pelo uso aparentemente absoluto entre os jovens. Por sua vez, o PPC apresenta um comportamento que caracteriza estruturas em vias de desaparecimento, isto é, menos recorrente, de modo geral, e favorecido por falantes mais velhos. Quanto ao funcionamento, identificamos um uso levemente acentuado do PPC em contextos que possibilitam uma leitura continuativa (verbos de estado), ao passo que o PPS é mais favorecido junto a verbos télicos e pontuais (achievement). Por fim, a observação da recorrência do PPC em orações interrogativas 
mostra-nos seu uso referindo-se a situações genéricas e potenciais ocorridas em uma extensão temporal menos definida.

\subsubsection{O AP ampliado}

Como já descrito, verificamos nesse subâmbito temporal a maior recorrência do PPC no corpus de Buenos Aires (45\%). Contudo, a análise do tipo de base verbal revela que com verbos estativos o percentual de ocorrências do PPC (58\%) torna-se maior que a do PPS (42\%). Esse é o cenário exemplificado no enunciado (19), no qual a forma do PPC refere-se a uma situação que ainda permanece no momento de fala ("ha tenido la suerte"). O valor continuativo é também reforçado pela expressão temporal durativa "en mi carrera".

(19) Cuando uno ha tenido la suerte, como en mi carrera, y haber trabajado al lado de las primeras figuras más importantes que hubo en el país [...]<B3>.

Quando alguém tem a sorte, como na minha carreira, e ter trabalho ao lado das primeiras figuras mais importantes que houve no país.

Em condição inversa, o perfeito simples parece se acomodar melhor com verbos pontuais $(63 \%)$ e télicos (58\%) - como apresenta o enunciado (20).

(20) Después me ganó creo que dos o tres veces de las veces que nos enfrentamos ¿no? También en Boca Vélez $<$ B $7>$.

Depois ganhou de mim acho que duas ou três vezes das vezes que nos enfrentamos, né? Também no Boca versus Vélez.

A análise quantitativa promovida pelo Goldvarb Yosemite seleciona também o grupo de fatores "número do sujeito gramatical”, atribuindo maior peso relativo ao traço plural $(0,69)$, contexto que favorece a ocorrência do PPC (67\%). Os enunciados (19) apresentam o uso do PPC no contexto em que são mais recorrentes, tendo em vista o número do sujeito. Em especial, como se observa no enunciado (21), ao se referir a um grupo de pessoas ("muchos compañeros") que padeceu ao longo da história, cria-se a percepção de que a situação referida se estende até próximo ao momento de enunciação - identificando, mais uma vez, o maior índice do PPC junto a um fator que favorece a leitura continuativa.

(21) Nosotros sabemos que estamos luchando por muchos compañeros que han quedado en el camino [a lo largo de la historia] $<$ B4 $>$.

Nós sabemos que estamos lutando por muitos companheiros que ficaram/tem ficado pelo caminho [ao longo da história]. 
Quanto à tipologia frasal, destaca-se a maior recorrência da forma simples em orações negativas e o maior percentual de uso da forma composta novamente em orações interrogativas - como em (22). Em especial, esse último dado merece uma atenção especial devido ao peso relativo que o fator "oração interrogativa" recebe sobre o uso do PPC ([0,81]).

(22) ¿Se han enfrentado alguna vez o esta es la primera vez? $<\mathrm{B} 7>$ Enfrentaram-se alguma vez ou esta é a primeira vez?

A exemplo do que comentamos na análise das orações interrogativas no AP específico, o enunciado (22) evidencia que, também no AP ampliado, o PPC pode fazer referência a uma situação genérica e pouco definida quanto ao tempo em que ocorreu (RODRÍGUEZ LOURO, 2009, 2011), isso porque o enunciador desconhece a efetividade do enfrentamento no passado, mas especula sobre possíveis encontros que eventualmente possam ter ocorrido em alguma ocasião desconhecida.

Aparentemente, esse sentido também pode ser preservado no uso da forma simples, tanto que, em (23), o enunciador faz referência a um acontecimento até então potencial (Qué click pasó) presumido pela situação atual do enunciatário -, sem saber a que situação pode estar se referindo concretamente, nem sequer o momento de sua realização. Contudo, é importante destacar o peso que tem esse fator na determinação do uso da forma composta em detrimento da simples, indicando que, nessa variedade diatópica, é o PPC que tem maior aceitabilidade em orações interrogativas, quando inseridas no AP ampliado.

(23) ¿Qué click pasó en tu vida que dijiste: "Bueno, ¡Sí! Ahora me largo”? <B3> Que click aconteceu na sua vida que você disse: "Bom, sim! Agora eu me jogo"?

Finalmente, o estudo das variáveis extralinguísticas segue indicando que, na variedade portenha, há maior recorrência do PPC entre homens (48\%); por sua vez, a forma simples mantém-se mais recorrente entre as mulheres (75\%). Tendo em vista que (i) o PPS ainda é a forma mais recorrente, de modo geral, na expressão do AP ampliado e (ii) que seu uso é ainda mais acentuado na fala feminina, parece possível afirmar que, a exemplo do observado no âmbito de AP específico, o PPS é a forma de maior prestígio nessa variedade diatópica para a expressão do AP ampliado. Contudo, conforme temos pontuado, a confirmação dessa relação entre a variável gênero/sexo e o uso do pretérito perfeito exige um estudo mais ampliado e sistematizado, que inclusive avalie o papel do homem e da mulher nas comunidades diatópicas abordadas por este trabalho.

Quanto à faixa-etária, observamos que entre os falantes menores de 35 anos apenas o PPS 
é encontrado, índice que diminui na fala dos maiores de 35 anos, chegando a $50 \%$ entre 35 e 55 anos. Por sua vez, o PPC apenas é identificado a partir dos 35 anos. Recordemos que também no AP específico dessa variedade diatópica foi possível delinear o cenário apontado pela descrição dos variáveis independentes no AP ampliado.

A síntese da análise multivariada dos dados do âmbito de AP ampliado em Buenos Aires aponta que a forma simples parece seguir desfrutando de um status de maior prestígio, posto que não apenas é a forma mais presente, de modo geral, nesse contexto de análise, mas parece se tornar ainda mais recorrente quando se observa a fala feminina e a população com idade intermediária. Numa tendência inversa, o PPC parece ser favorecido entre os homens e os falantes mais velhos, comportamento que, a exemplo do observado no AP específico e no trabalho de Kubarth (1992), pode ser indício de que a forma composta tenda à diminuição no uso à medida que se progrida na troca de gerações.

Uma vez apreciado o contexto de $\mathbf{A P}$, passemos à observação do $\mathbf{P A}$.

\subsection{O passado absoluto}

Conforme descrito, ao passado absoluto se atribui a expressão de situações pretéritas concluídas no passado e que já não mantêm relação temporal direta com o MF (Figura 1), pois os fatos descritos passam a ser contemplados a partir de uma perspectiva de pretérito, isto é, que tem seu término definido anteriormente ao momento em que se enuncia $(\mathrm{O}-\mathrm{V})$. Considerando a orientação normativa sobre o uso do pretérito perfeito nesse âmbito temporal, vimos que o PPS é tratado como a forma própria desse contexto (BELLO, 1972, 1999; KANY, 1970; GILI GAYA, 1970; ALARCOS LLORACH, 1980, 2005; RAE, 1986, 2009, 2010; ROJO, 1980, 2005; TORREGO, 2002). Esse é o uso observado nos enunciados abaixo, nos quais "el año pasado" e "ayer" evidenciam a referência temporal de PA:

(24) El año pasado estuve haciendo la consigna de Arnold Wesker $<\mathrm{B} 3>$.

$\mathrm{O}$ ano passado estive fazendo a proposta do Arnold Wesker.

(25) Ayer hicieron su regenerativo y ya se trabajó todo el grupo junto. $<\mathrm{B} 7>$.

Ontem fizeram seu regenerativo e todo o grupo já foi trabalhado junto.

Contudo, contrário ao descrito na norma gramatical, também encontramos no corpus compilado o uso da forma composta no contexto temporal de PA. Esse é o caso, por exemplo, dos seguintes enunciados: 
(26) $[\ldots]$ hemos dejado una base enorme el año pasado $<B 6>$.

$[\ldots]$ deixamos uma base enorme ano passado.

(27) Mi labor específica y la labor de mi grupo es llevar dignidad, por ejemplo, como lo hemos hecho el domingo pasado, en el anfiteatro del parque Centenario $[\ldots]<\mathrm{B} 1>$.

Meu trabalho específico e o trabalho do meu grupo é levar dignidade, por exemplo, como o fizemos domingo passado, no anfiteatro do parque Centenário [...].

Diante desses dados e conforme sintetiza a Tabela 3, é possível encontrar o uso do PPC também no contexto de passado absoluto no corpus de Buenos Aires (2\%), ainda que muito discreto diante do uso da forma simples (98\%).

Tabela 3: Da expressão do passado absoluto em Buenos Aires

\begin{tabular}{c|c|c}
\hline PPC & 8 & $2 \%$ \\
\hline PPS & 344 & $98 \%$ \\
\hline Total & 352 & $100 \%$ \\
\hline
\end{tabular}

Tendo em vista o uso quase categórico do PPS (98\%) nesse contexto de análise, a discussão seguinte irá se restringir apenas a apontar os fatores que, de alguma maneira, contribuem para que a forma composta ainda possa ocorrer, mesmo que de forma discreta.

A análise multivariada dos dados indica uma tendência diferente do que descrevemos nos subâmbitos de antepresente. Isso porque, no passado absoluto, a forma composta deixa de ser percentualmente mais recorrente junto aos fatores linguísticos que evidenciam uma leitura de continuidade e passa a ser mais recorrente em contextos com uma leitura perfectiva. Conforme se observa no gráfico 1, o PPC tem o uso concentrado junto a verbos télicos (3\%) e pontuais (4\%).

Gráfico 1: Dos grupos de fatores que favorecem a leitura de perfectividade no âmbito de passado absoluto

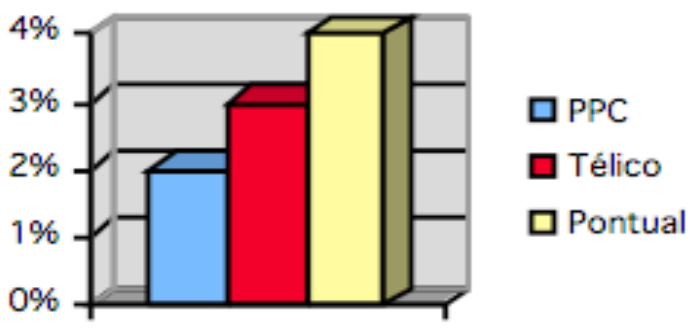

Fonte: reprodução do autor. 
A fim de melhor avaliar esses resultados, vejamos, a seguir, os enunciados encontrados nesse contexto de análise:

(28) Mi labor específica y la labor de mi grupo es llevar dignidad, por ejemplo, como lo hemos hecho el domingo pasado, en el anfiteatro del parque Centenario $[\ldots]<\mathrm{B} 1>$.

Meu trabalho específico e o trabalho do meu grupo é levar dignidade, por exemplo, como o fizemos domingo passado, no anfiteatro do parque Centenário [...].

(29) Hace unos días atrás hemos recibido, desde la legislatura porteña [...] una invitación a un recital por el monumento a la mujer originaria. [...] Que se realizó el sábado, veinticinco de septiembre, en diagonal sur y Perú $<\mathrm{B} 2>$.

Há uns dias atrás, recebemos, da câmara portenha [...] um convite para o recital pelo monumento à mulher originária. [...] Que se realizou no sábado, vinte e cinco de setembro, na avenida diagonal sul, com a rua Peru.

(30) [...] esto ha generado en su momento mucha polémica. A ver, yo entiendo que a una figura como la de Roca se le apremia con el billete más caro o de más valor en nuestro país ¿no? Eh... con los cien pesos. Y a otras figuras, como San Martín, se lo ponen en los billetes de cinco ¿no? <B2>

[...] isso gerou, no seu momento, muita polêmica. Olha, eu entendo que uma figura como a de Roca é reconhecida coercitivamente com a nota mais cara ou de mais valor em nosso país, né? É... com os cem pesos. E outras figuras, como San Martín, são colocadas nas notas de cinco, né?

(31) Tati siempre nos dice que es la tarea de los organismos de derechos humanos. Nosotros hemos constituido uno [en diciembre]. El archivo de la memoria de la diversidad sexual. Tienen la tarea de mantener vivo esto, porque si la gente se olvida, mira lo que pasa $<$ B4 $>$.

Tati sempre nos diz qual é a tarefa dos organismos de direitos humanos. Nós constituímos um [em dezembro]. O arquivo da memória da diversidade sexual. Têm a tarefa de manter vivo isso, porque se as pessoas se esquecem, olha o que acontece.

(32) Habría que ir por el título de algún profesional que ha dicho esas cosas [en aquella ocasión], porque han violado leyes, diciendo esas mentiras, barbaridades obscurantistas $<$ B4 $>$.

Deveriam cassar o título de algum profissional que disse essas coisas [naquela ocasião], porque violaram leis, dizendo essas mentiras, barbaridades obscuras.

(33) Has terminado un estudio... un sondeo, hace poquitos días ¿no? $<$ B5 $>$ Você concluiu um estudo... uma pesquisa de intenção de votos há poucos dias, não é?

(34) $[. .$.$] hemos dejado una base enorme el año pasado y que ahora le llegaron un montón de$ 
jugadores que son de nivel óptimo $<\mathrm{B} 6>$.

Deixamos uma base enorme no ano passado e que agora chegou pra ele um monte de jogadores que são de ótimo nível.

Observamos nos enunciados (29), (31), (33) e (34) situações (“hemos recibido una invitación", "hemos constituido uno", "has terminado un estudio", "hemos dejado una base enorme", respectivamente) pontuais e télicas (achievement) que não só descrevem ações perfectivas, mas parecem repercutir, de alguma maneira, no momento presente. De modo mais pontual, em (29) o contraste entre o PPC ("hemos recibido") e o PPS ("realizó") permite-nos observar, respectivamente, o enunciador destacar aquilo que lhe confere e que lhe dá lugar de destaque ("receber o convide do próprio poder legislativo"), daquilo que objetivamente ocorreu no tempo e espaço ("recital pelo monumento à mulher originária").

Na mesma direção, em (31) e (34), os enunciadores parecem enfatizar, por meio da forma composta, que seu trabalho ("hemos constituído uno" e "hemos dejado una base") não apenas é relevante, mas ainda traz consequências ao momento da enunciação. Assim, apresenta, de maneira explícita, qual é o resultado presente de sua intervenção no passado ("mantener vivo" e "le llegaron un montón de jugadores"). Em especial, em (34), observa-se mais uma vez a contribuição da oposição entre as formas composta e simples para a argumentação desenvolvida pelo enunciador, de maneira que, com o PPC ("hemos dejado"), trata-se como especialmente relevante a ação realizada por ele e, com o PPS ("llegaron"), apresenta-se o resultado, mais recente, da situação previamente desenvolvida.

Finalmente, em (33), parece ser possível inferir, com o uso da forma composta (“has terminado"), a valoração de uma informação nova, a qual deve contribuir para um maior esclarecimento sobre o posicionamento do eleitorado sobre o cenário político em discussão.

Devido ao valor de duração que os verbos de accomplishment também apresentam, verifica-se a presença discreta desse valor nos enunciados (28), (30) e (32), já que "hacer algo", "generar mucha polémica", "decir esas cosas" - respectivamente -, demandam certo período de desenvolvimento antes de chegar a sua conclusão. Apesar dessa característica, é importante também destacar que se soma aos verbos de accomplishment o traço de "telicidade", o que nos permite observar as referidas ações como perfectivas, isto é, terminadas. Em complemento, a exclusiva recorrência de marcadores temporais de passado, sem informação durativa, corrobora a leitura perfectiva identificada, de modo geral, nos dados expostos.

Tendo em vista que é possível encontrar, em Buenos Aires, o uso do PPC também fazendo 
referências a situações genéricas ocorridas em um passado indefinido (RODRÍGUEZ LOURO, 2009, 2011), os dados do PPC parecem indicar que esse comportamento não é tão evidente no contexto de PA. Pois, com exceção de (32), as demais ocorrências do PPC fazem referência a fatos efetivamente identificados ("lo hemos hecho", "hemos recibido una invitación", "ha generado mucha polémica", "hemos constituido uno", "has terminado un estudio", "hemos dejado una base") e pertencentes a um momento definido do passado ("el domingo pasado", "hace unos días atrás", "en su momento", "en diciembre", "hace poquitos dias").

Contudo, a observação do enunciado (32) revela que o uso do PPC fazendo referência a situações genéricas em uma envoltura temporal menos definida ocorre justamente em um contexto linguístico em que o sujeito é menos determinado. Tanto é que, no enunciado em questão, ele é modificado por um adjetivo indefinido (“algún”) ou está ausente - em um verbo conjugado na terceira pessoa do plural e com o agente indeterminado ("han violado leyes"). Ademais, a soma de um complemento verbal plural corrobora a imprecisão informativa ("esas cosas/leyes"), haja vista que não se sabe exatamente o número de vezes ou quando as coisas foram ditas/leis foram violadas.

No que diz respeito aos grupos de fatores extralinguísticos, a análise do gênero/sexo dos falantes apresenta aparentemente um padrão equilibrado do uso do PPC. Por sua vez, os resultados para a variável faixa etária apontam, no gráfico 2, que a forma composta apresenta um padrão de uso mais conservador, posto que não é encontrada entre os mais jovens, sendo que os poucos dados se concentram entre falantes de idade entre 36 e 55 anos - grupo seguido pelos mais velhos (maiores de 55 anos).

Gráfico 2: Da incidência percentual do grupo de fatores "idade" sobre o uso do PPC no âmbito de passado absoluto, segundo os dados de Buenos Aires

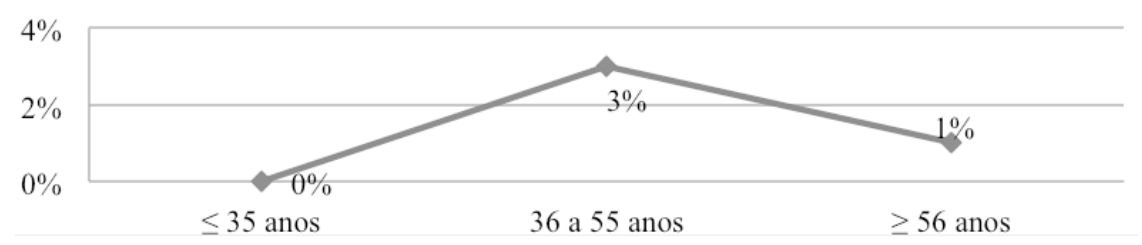

Fonte: reprodução do autor.

Em suma, o estudo do PPC no âmbito de PA em Buenos Aires revela que essa forma aparentemente deixa de ser mais recorrente em contextos que exprimem um sentido de duração, ao passo que é discretamente mais recorrente junto a traços linguísticos que operam na construção de situações perfectivas. Característica que parece indicar um uso com valor de relevância presente. Além disso, é provável que a referenciação a situações genéricas ocorridas em um passado menos definido também se realize por meio do uso do PPC - sobretudo quando junto a traços que favorecem 
a descrição de situações menos definidas, tais como a marcação de plural e marcadores de tempo indeterminado.

Sobre o aspecto extralinguístico, os dados parecem reproduzir a tendência já identificada no contexto de AP, isto é, a concentração de seu uso entre os mais velhos. Uma vez que o PPS apresenta uso quase que categórico nesse contexto e que os jovens recorrem apenas a ele para expressar o PA, parece haver uma tendência à intensificação do desuso do PPC nesse âmbito.

Por fim, tendo em vista a escassez dos dados, as tendências delineadas requerem um estudo mais estendido e apurado, em pesquisas futuras, do funcionamento do PPC no passado absoluto. Por outro lado, a expressiva recorrência da forma simples em todos os cenários contemplados evidencia não apenas a vitalidade dessa forma em Buenos Aires, mas também seu prestígio na expressão do passado absoluto.

\section{Considerações finais}

A síntese da discussão apresentada neste trabalho permite-nos delinear uma tendência crescente da forma composta no âmbito de antepresente à medida que se dilata a amplitude da referência temporal. Assim, o uso categórico da forma simples no contexto de AP imediato vai debilitando-se com o aumento no percentual do PPC no AP específico (13\%) e, de maneira ainda mais intensa, no AP ampliado (45\%). Uma vez que, de modo geral, a forma composta é mais recorrente entre a população mais velha e o PPS, entre os mais jovens, o avançar do processo de mudança na expressão do antepresente e de seus subâmbitos deve culminar na diminuição mais acentuada no uso do PPC, em favor do uso absoluto do PPS.

Por outro lado, a observação do comportamento do PPC no âmbito de passado absoluto revela uma diminuição brusca no uso do PPC (2\%) ao devolver, de modo quase categórico, ao PPS a expressão do passado absoluto - conforme prevê a norma-padrão. Em suma, notamos que nessa variedade diatópica, os subâmbitos de AP específico e de AP ampliado são os que mais favorecem o estudo da variação entre as duas formas do pretérito perfeito, posto que neles o PPC tem um percentual de uso incrementado.

Por fim, considerando os estudos já existentes sobre o tema, os dados deste trabalho concordam com os estudos de Kubarth (1992), García Negroni (1999), Rodríguez Louro (2008, 2009, 2010 e 2011), Oliveira (2010), posto que identificam a forte correlação entre os valores de continuidade e/ ou relevância presente e o PPC. Ainda segundo Kubarth (1992), o fator âmbito temporal não incide na seleção de uma das formas na modalidade falada, em Buenos Aires. Porém, os dados apresentados 
nesta pesquisa demonstram que é possível observar um incremento no uso do PPC à medida que ampliamos a dimensão temporal, dentro do âmbito de AP. Dessa maneira, uma afirmação como a defendida por Kubarth (1992) requer um melhor refinamento.

\section{REFERÊNCIAS}

ALARCOS LLORACH, E. (1980). Perfecto simple y compuesto. In: ALARCOS LLORACH, E. Estudios de gramática funcional del español. 3 ed. Madrid: Gredos. p.13-49.

. (2005). Gramática de la lengua española. Madrid: Espasa.

ARAUJO, L. S. (2012). Os valores atribuidos ao pretérito perfecto compuesto espanhol nas regiões dialetais da argentina. 2012. 212 f. Dissertação (Mestrado em linguística e língua portuguesa) - Faculdade de Ciências e Letras, Universidade Estadual Paulista "Júlio de Mesquita Filho", Araraquara, 2012.

. (2013). O pretérito em espanhol: usos e valores do perfecto compuesto nas regiões dialetais argentinas. São Paulo: Cultura Acadêmica.

. (2015). O estudo da temporalidade verbal na língua espanhola: contribuições à dialetologia argentina. In: COSTA, Daniel Soares da. (Org). Pesquisas linguísticas pautadas em corpora. São Paulo: Editora Unesp Digital. p. 111-152.

. (2017). O gênero entrevista radiofônica em comunidades hispânicas: um aporte da Análise Textual Automática. Domínios delingu@gem, v. 11, p. 289-312.

BALDINGER, K. (1966). Semasiologia e onomasiología. Alfa, Marília, v. 9, p. 7-36.

BELlO, A. (1972). Análisis ideológico de la conjugación castellana. Caracas: Plan Cultural Caracas.

. (2004). Gramática de la lengua castellana. Madrid: EDAF.

BENVENISTE, E. (2005). Problemas de linguística geral. 5 ed. Trad. Maria da Gloria Novak e Maria Luisa Neri. Campinas: Pontes. 1 v.

CARTAGENA, N. (1999). Los tiempos compuestos. In: BOSQUE, I.; DEMONTE, V. Gramática descriptiva de la lengua española. Madrid: Espasa. 2 v. p. 2933-2975.

DE GRANDA, G. (2003). Estudios lingüísticos hispanoamericanos: historia, sociedades y contactos. Frankfurt: Peter Lang. 
GARCÍA NEGRONI. M. M. (1999). La distinción pretérito perfecto simple/pretérito perfecto compuesto. Un enfoque discursivo, Revista iberoamericana de discurso y sociedade, Barcelona, v. 1, n. 2, p. 45-60.

GILI GAYA, S. (1970). Curso superior de sintaxis española. 9 ed. Barcelona: Biblograf.

GUTIÉRREZ ARAUS, M. L. (2001). Caracterización de las funciones del pretérito perfecto en el español de América. In: CONGRESO INTERNACIONAL DE LA LENGUA ESPAÑOLA, $2^{\circ}, 2001$, Valladolid. Paneles y ponencias del II Congreso Internacional de la Lengua Española. Madrid: Centro Virtual Cervantes.

HERNÁNDEZ ALONSO, C. (1996). Gramática funcional del español. 3 ed. Madrid: Gredos.

JARA YUPANQUI, I. M. (2009). El pretérito perfecto simple y el pretérito perfecto compuesto en las variedades del español peninsular y americano. Signo e Seña. Buenos Aires, n. 20, p.255-281. KANY, C. E. (1970). Sintaxis hispanoamericana. Trad. Martín Blanco Álvarez. Madrid: Gredos. KUBARTH, H. (1992). El uso del pretérito simple y compuesto en el español habladi de Buenos Aires. LUNA TRAILL, E. G. (Coord). Scripta philologica: in honorem Juan M. Lope Blanch. Ciudad de México. 2 v. p.553-566.

LAMIQUIZ IBAÑEZ, V. (1969). El sistema verbal del español actual. Revista de la Universidad de Madrid: Homenaje a Menéndez Pidal. Madrid, v. 18, p.242-267.

LENZ, R. (1929). La oración y sus partes. Madrid: Centro de Estudios Históricos.

MORENO FERNÁNDEZ, F. (2000). Qué español enseñar. Madrid: Arco Libros.

MÚGICA, N. (2007). Acerca de la tensión norma - variación lingüística. Sintaxis, morfología, léxico. Revista Virtual de Estudos da Linguagem. v. 5, n. 9.

OLIVEIRA, L. C. (2007). As duas formas do pretérito perfeito em espanhol: análise de corpus. 2007. 130 f. Dissertação (Mestrado em Linguística) - Universidade Federal de Santa Catarina, Florianópolis.

. (2010). Estágio da gramaticalização do pretérito perfeito composto no espanhol escrito de sete capitais hispano-falantes. 2010. 263 f. Tese (Doutorado em Linguística) - Universidade Federal de Santa Catarina, Florianópolis.

RAE. (1986). Esbozo de una nueva gramática de la lengua española. Madrid: Espasa, 1986. . (2009). Nueva gramática de la lengua española: Morfología y Sintaxis I. Madrid: 
Espasa. $1 \mathrm{v}$.

(2010). Manual de la nueva gramática de la lengua española. Madrid: Espasa.

REICHENBACH, H. (2004). The tenses of verbs. In: STEVEN, D.; GILlON, B. S. (Orgs.). Semantics: a reader. New York: Oxford University Press. p.526-533.

RODRÍGUEZ LOURO, C. (2008). Usos del Presente Perfecto y el Pretérito en el español rioplatense argentino. In: CONGRESO INTERNACIONAL DE ALFAL, 15, 2008, Montevideo. Actas del XV Congreso Internacional de ALFAL. Montevideo: Alfal.

. (2009). A sociolinguistic study of Preterit and Present Perfect usage in contemporary and earlier Argentina. 2009. 288 f. Tese (Doutorado em Filosofia) - School of Languages and Linguistics, Faculty of Artsisêp, University of Melbourne. Melbourne.

. (2010). Past Time reference and Present Perfect in Argentinian Spanish. In: TREIS, Y.; DE BUSSER, R. (Eds). Selected Papers from 2009 Conference of the Australian Linguistic Society. Melbourne: La Trobe University. p. 1-24.

.; JARA YUPANKI, M. (2011). Otra mirada a los processos de gramaticalización del presente perfecto en español: Perú y Argentina. Studies in hispanic and lusophone linguistics. Minnesota, v. 4.1, p.55-80.

ROJO, G. (1974). La temporalidad verbal en español. Verba: Anuário Gallego de Filología, Santiago de Compostela, v. 1, p.69-149.

. (1990). Relaciones entre temporalidad y aspecto en el verbo español. In: BOSQUE, I. (Org.). Tiempo y aspecto en español. Madrid: Cátedra. p.17-43.

.; VEIGA, A. (1999). El tiempo verbal: los tiempos simples. In: BOSQUE, I.; DEMONTE, V. Gramática descriptiva de la lengua española. Madrid: Espasa. 2 v. p.2867-2934.

SANTOS, C. F. (2009). Variação e mudança linguística dos pretéritos simples e composto, uma perspectiva sociolinguística e discursiva: amostras de Madrid, Cidade do México e Buenos Aires. 2009. 259 f. Dissertação (Mestrado em Letras Neolatinas) - Faculdade de Letras, Universidade Federal do Rio de Janeiro, Rio de Janeiro.

TORREGO, L. G. (2002). Gramática didáctica del español. 8 ed. Madrid: SM.

VIDAL DE BATTINI, B. E. (1964). El español de la Argentina: Estudio destinado a los maestros de las escuelas primarias. Buenos Aires: Consejo Nacional de Educación. 